\title{
UNIVERSITYOF
}

FORWARD

THINKING

WESTMINSTER用

WestminsterResearch

http://www.westminster.ac.uk/westminsterresearch

The beginning of a beautiful relationship: A case study on an immersive filmmaking process.

Patel, S., Toulson, R. and Azuaje, L.

Patel, S., Toulson, R. and Azuaje, L. (2020) The beginning of a beautiful relationship: A case study on an immersive filmmaking process, in: Batty, C., Berry, M., Dooley, K, Kerrigan, S. and Frankham, B. (eds.) The Palgrave Handbook of Screen Production Palgrave Macmillan. Reproduced with permission of Palgrave Macmillan.

This extract is taken from the author's original manuscript and has not been edited. The definitive, published, version of record is available here: [insert URL for product on https://www.palgrave.com/gp/book/9783030217433

The WestminsterResearch online digital archive at the University of Westminster aims to make the research output of the University available to a wider audience. Copyright and Moral Rights remain with the authors and/or copyright owners.

Whilst further distribution of specific materials from within this archive is forbidden, you may freely distribute the URL of WestminsterResearch: ((http://westminsterresearch.wmin.ac.uk/)).

In case of abuse or copyright appearing without permission e-mail repository@westminster.ac.uk 


\section{The beginning of a beautiful relationship: A case study on an immersive filmmaking process.}

Shreepali Patel, Rob Toulson and Louis Azuaje

Book chapter in The Palgrave Handbook of Screen Production (2020)

\section{Introduction}

In 2007 filmmaker (and co-author), Shreepali Patel was asked to document an art installation, Journey (2007) curated by the human rights activist and actress, Emma Thompson. The installation recorded a journey of a young trafficked woman based on the first-person testimony by a young girl trafficked through the offer of hope and a better life. Journey (2007) was designed to be an experiential and physically immersive experience which would allow the audience to 'feel for 5 minutes' what it would be like to be trafficked. The installation consisted of 7 containers each designed by a different artist, creating their own individual interpretation of an element of the young girl's journey. A few years later, a digital version of the exhibition was suggested which Patel started crafting, called The Crossing (2017). This multi-platform project was designed to play out to multiple stakeholders including those directly vulnerable to trafficking techniques and audience responses, detailed below, capture how exhibition visitors became emotionally and psychologically involved in the human trafficking story The Crossing (2017). This chapter focuses on the production and post-production processes, the cross-disciplinary teamwork and the relationship between the director's vision - ideation, story, creative concepts - and its effective realisation through sound design, cinematography, visual effects and editing. This collaborative creative practice account of the making of The Crossing reveals how this multi-award winning, immersive and impactful project on trafficking was realised.

\section{The Crossing: Project and Exhibition}

The Crossing describes a young woman's journey through the world of human trafficking lured by the 'lover boy' technique (Patel, The Conversation, 2017). She breaks out of this world metaphorically by walking through an imperceptible glass prison. The glass symbolizes the breaking and fragmentation of a human being who has been through a process of mental and physical slavery. The point of breakage represents breaking free of the physical slavery with glass shards embedded within the images of her journey reflecting this. But the 
mental fragmentation (between body and soul) continues to exist. Based on first person testimonies and human trafficking reports (ILO 2014; UNODOC, 2014) the script drew on universal themes articulated by survivors, such as the 'destruction of identity' 'betrayal' and a separation of 'body from soul' to survive. A montage of visual narrative fragments tied together by a linear narration, immersive sound design underpinned by visual effects and graphics were built into the design.

The exhibition played in galleries across the UK and internationally as a multi-screen exhibition, split screen and as a physical 360. Feedback and audience observations from the screenings showed that the iterative, complex communication process proved to be an invaluable audience experience.

A truly engaging and immersive experience. Visceral soundscape affects me on a bodily level, hits my gut, makes my toes curl. (Crossing Roads, Visitor, 2016)

I didn't realise the extent of the issue and the huge financial gain made by the people behind it. (Ruskin Gallery Visitor, May 2016)

I was absolutely stunned, horrified and felt all sorts of physical effects whilst in the gallery - goosebumps, tears, lump in throat, breath catching. It will stay with me. (Ruskin Gallery Visitor, May 2016)

These testimonies describe the powerful visceral experience created by Patel as Director, Rob Toulson as Sound Designer and Louis Azuaje working in Visual Effects. This team carefully designed their disciplinary elements to create an emotional swing for both the film's central character and the audience between a state of drifting away from the real world and reemerging through the manipulation of images and soundscape. Milan Milicevic (2014) describes this creative conceit as a paradoxical experience, where the scenes in a film are seemed as almost impossible but are accepted as reality with the full emotional and psychological involvement of the viewer. The final story is told through a number of interconnected screens using intense sound design and perspective shifting visuals focusing on the experience of a young girl, from initial trust, exploitation of hope, entrapment, betrayal, a cycle of physical and mental abuse to release. However, the mental impact is long lasting and the cycle of abuse continues. The artist / filmmaker Steve McQueen calls attention to the reciprocal role between the director and audience which is essential to trigger 'bigger thoughts'. The director can orchestrate unanticipated connections to be discovered as an image creates a relationship among diverse elements of form and experience. 
You as the viewer have to project your own relationship to what you see...art is just a mechanism ... to impose upon the viewer for them to have bigger thoughts than the actual piece. (McQueen, 2009)

The production team (sound, visual effects, cinematography and drone filming) were encouraged to consider ways of creatively conveying information about human trafficking that could evoke (new) understandings of the more hidden issues involved. The process for The Crossing required collaboration within an interdisciplinary environment via the construction of a common language and workflow process and as such a shared ownership in the development and realisation of the project was advocated and innovative co-working and communication approaches was encouraged. Often this required descriptive language or use of musical tone to convey the 'feeling' of what needed to be achieved, or returning to the narrative to emphasise the emotional shifts at key points in the story.

\section{The Crossing: Principal Photography}

Principal photography took the form of three specific formats: projection, live action drone and slow motion studio (providing the foundation for the visual effects of the glass breaking scene). Projections representing different elements of our protagonist's story were projected onto the actor's body. These included ticker tape data used by stock exchanges and locations of where she came from to where she travelled through. These were filmed in a small studio over the course of two days. The drone footage was captured in London from dawn to dusk, predominantly in landmark environments (the financial quarter near St. Paul's Cathedral and Kings Cross Station). The filming team were able to 'play' with the environment and capture analogous autumnal footage (leaves blown by the blades on the drone) and the atmosphere of the fog laden South Bank lit by the necklace of lights along the river and on London Bridge. This day of filming took over 4 months to secure in terms of airspace in line with Civil Aviation Authority regulations for flying within urban environments. The slow-motion footage of our protagonist walking towards the audience was one of the most complex to set up. Studio space with the exact length to film the walk towards camera to time with the pretimed breakage was difficult to secure initially, but this was eventually filmed in one day providing the footage needed for the Visual Effects (VFX) team.

\section{The Crossing: Visual Effects}

Using VFX on The Crossing allowed Patel to consider adding extra textural layers to enrich the story. The analogous glass breaking scene could not be achieved using conventional 
filmmaking techniques, and construction through Computer Generated Imagery (CGI) was the most feasible and creative approach. Following a prototype testing phase, the VFX team were tasked with developing a fully computer generated glass pane. Venkatasawmy (2012) asserts VFX is used in one of four ways in filmmaking: visually, its main purpose is to create an effect that is original in concept and delivery; the brief for the visual on The Crossing clearly fall into this category; enhancing, add an extra level of intensity and augmentation to the plot in general; substituting, replacing the real with the virtual as a cost-saving technique, and finally concealing, the technological devices used in the past three categories

The versatility and convenience of $3 \mathrm{D}$ computer graphics makes it a powerful tool to speed up processes on a tight deadline and update obsolete production pipelines. This creates a wider room to pool and convey new approaches and ideas by emerging and current innovative creative practitioners operating within film and media. These developments have complemented and expanded the most important elements in film production - story and character. Though critics such as Sam Wijaya argue the use of highly sophisticated visual effects in film is not necessarily a winning formula for good audience acceptance or financial success (Wijaya, 2017), "There is no amount of spectacle that will compensate completely for the lack of good story or compelling characters" (Humans Invent, 2013). Ross and Squires (2013) note that the implementation of visual effects can add to a character's development by providing a visual richness and detailed complexity of production, artefacts that might have been impossible to accomplish with more traditional techniques developed during the early days of practical effects. In some circumstances we can admit that the use of visual effects enhances storytelling in a production, as Lasseter suggests "The art challenges the technology, and the technology inspires the art" (Catmull, 2014).

The slow-motion live action on set was shot at 240 frames per second (FPS). The VFX team had to gather as much data as possible to match the physical camera with its CG digital version. Variables such as depth of field, distance from subject, camera position location, frame rate, aspect ratio, lens distortion and location of physical lights would prove critical to match and time the digital glass with the actress's performance. As such recording the physical light positions, set dimensions, and a series of sequences of real glass shards on set were invaluable as references to adjust the correct depth of field of the CG shards during the compositing and reduce valuable rendering time in the later stages of post-production. A 
virtual camera was constructed from the data variables, which was set and matched to the correct specifications required using the tools available on the 3D content creation software, in this case, Autodesk Maya. A virtual actress was created through modelling, and this figure represented a simplified version of the real life actress. This 3D model was rigged and key framed animated to match as closely as possible to the movement of our original actress. The virtual actress was our collision object, designed to trigger the animation of the shards inside the simulation process. To key frame animate this model, the footage was converted to play at a standard rate of 24 FPS. This new animated sequence was used to art-direct the exact moment the glass breaks.

The glass fragments were particularly problematic to discuss across the team because of discipline specific language, the director's limited knowledge of software capability and application impacting upon the workflow. In order to overcome this and create a common visual language, the team developed a numbering system for specific glass shards (see Figure 1) called 'hero' shards within a simulation of the movement of the glass shards was created with a digital frame. An iterative workflow was designed around a series of screenshots and videos with an embedded timecode operating to frames which were shared with the whole team.
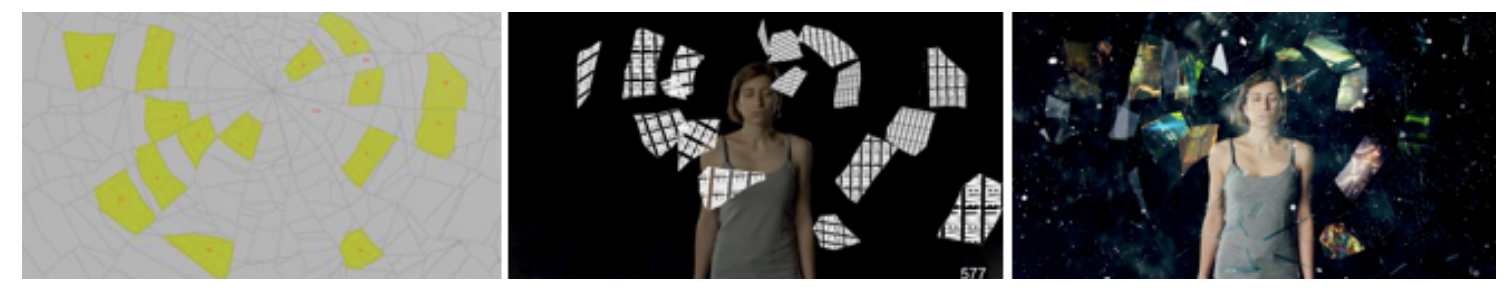

Figure 1. Shard numbering system from digital simulation to final delivery

The glass shards sequence was imported into the main simulation and rendering platform, SideFX Houdini (chosen because of its flexibility and robust performance in Rigid Body Dynamics, RBD). One key element behind the realism of the glass shards was the creation of a flexible tool that allowed the director to change and iterate different patterns combinations. This tool facilitated the creative process by interactively controlling the number of shards, the position and point of impact and the level of texture details on the shard itself. The shards were animated using Houdini's RBD, with initial tests running over 500 individual shards on the simulation pipeline. This process shed light into the complexity and challenges ahead of 
the project, including the timing and speed of the simulation. Running a simulation at 240 FPS was not feasible or stable, so a retime mechanism was set in place to run the simulation at 24 FPS and retime later on at 240 FPS. The RBD of the glass shards was crucial to convey the realism and impact intended by the sequence. Within this simulation, the director selected some of the shards to display key moments from the story. In total, 6 different simulations layers were run: the main shards simulation; the hero simulation; the initial burst of small shards; a glass dust trail of the main shards; a thin smoke trail of particles produced by the break; and the glass dust rolling within the smoke particles, as shown in Figure 2.

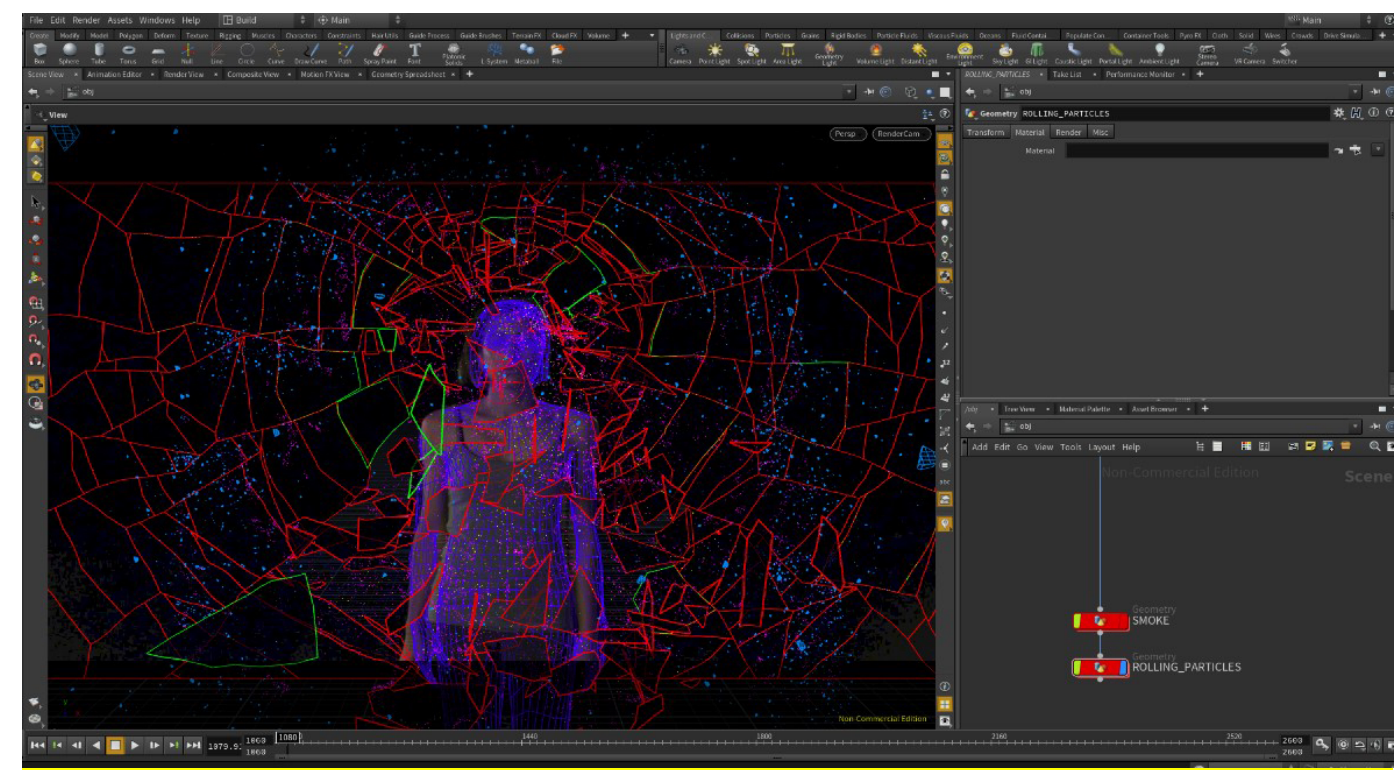

Figure 2. Colour Coded Simulation including fragmentation and dust

The lighting stage proved to be very unconventional. In a normative scenario, a series of virtual lights would be placed strategically within the environment that resemble the original place in the real-world space in order to light the CG scene. For The Crossing however, this was not the case as the main character emerged from the darkness without any additional lighting. Therefore, the scene lacked any reflections or refractions, which one would normally get from lit glass. In order to construct the reflections, a 3D representation of the soft box lighting used during the filming was strategically placed within the digital frame to simulate the reflection of the live action plates.

The rendering was processed using Houdini's proprietary renderer Mantra, a built-in renderer. Due to the frame rate of the film (240fps), there were 10 times more frames to render in order to produce a single second of animation; to overcome this demand, a small inhouse render farm was set-up to handle the rendering needed to produce the glass sequence. 
At the end of the project, over 600,000 images were rendered over a period of 2 weeks. The communication between the VFX artist and the compositor proved key to develop a seamless workflow of data exchange and producing the final colour, movement and image of the final glass shards.

\section{The Crossing: Sound Design}

The sound design was constructed almost simultaneously to the VFX movement of the glass shards. The Sound design for The Crossing involved multiple cross-disciplinary collaborations that required unconventional approaches and synthesis of working practice including the use of non-linear and parallel sound and picture editing, with each informing the other. In many conventional, linear, sound design productions, the sound designer is given an edited film that is visually complete, with sound design then being choreographed to the locked picture, as described for example by Yewdall (2007) and Rose (2009), who state:

It doesn't make sense to start serious editing of the track until the picture is finished ... If you're making a TV show or sales video, postproduction happens on a schedule: picture gets locked, sound gets completed, job gets done. (Rose, 2009, p103)

Rose does however concede that

Movies don't work that way. Directors want to keep fine tuning their story, almost until it gets shown on the screen, and that can mean [the sound editor] building a finished track even though the picture will still change. (Rose, 2009, p103).

For The Crossing, a more contemporary and non-linear approach was adopted, which implements and extends the methods proposed by Dykhoff (2016), who argues: 'Because sound and image influence each other so much, it would make sense for communications to flow both ways. In a linear workflow, this is impossible.' This workflow method is empowered by the ability to regularly share digital work-in-progress on a daily basis between the editor and sound designer, through exchanges of portable hard drives and online storage and sharing facilities.

As The Crossing is a narrated story of a female victim's entrapment and subsequent escape from sex slavery, spoken word sound drives the entire feature. The development of the script, voice recording and post sound editing are therefore integral in initiating the post-production filmmaking process. After the voiceover recording had been edited and a timeline for the whole feature was mapped, the picture and sound design teams were then able to proceed in 
parallel. At this point the director's role became critical as they oversaw the daily progress of these two disciplinary teams.

\section{The Crossing: Directorial Vision}

The Crossing, was designed as a multi-screen project, utilising multiple layered images displayed across thirteen digital screens.' Creating this multi screened work required a precise yet unconventional workflow between three teams, because unlike a linear film, the editing, sound design and visual effects teams were not working to a single visual linear representation. The pace, timing and rhythm of the visuals and sound for each digital screen were created using a non-linear sound and picture workflow that was iterative. This meant there were three teams working in parallel, the editing, sound design and visual effects teams were creating, sharing and adjusting their sections daily. The director's workflow began with the film editor, who made and shared daily picture-in-picture renders of the feature, displaying the most significant scenes. This allowed the director to work with the sound designer on the multilayer visual scenes, and to use the sound design to cue edits and cuts between scenes. So on consecutive days the driving component of the editing would flip from sound to picture, and then back to sound. An example of this is where the director and sound designer evaluated the pacing of the story, as told through sound, and identify the natural sonic envelopes for phrases and effects. This occurred when adjusting the sonic duration of a diegetic train fading to silence, the sound designer and director agreed to the precise length, and the next day the visual editor had to adjust the visual scene of a train to synchronise with the sound. The director had to keeping track of this unconventional workflow, to maintain their vision and the co-ordination of these cross-disciplinary decisions was carefully manged so all components would be perfectly synchronised to achieve the multi-screen immersive experience.

The visual effects team who created the animated effects for the glass breaking sequence discussed earlier, were also sharing their work and receiving updated scenes from the sound designer and the editor. During days when the video edit was being manipulated, the sound design team could be progressing with development of sound and effects to accompany the animated glass breaking scene. This collaborative parallel workflow was necessary because

\footnotetext{
${ }^{1}$ The original gallery exhibitions used thirteen screens, and this was later arranged within a single split screen for a more traditional cinema display.
} 
of the significant amount of time required for designing, programming and rendering the glass breaking scene and embedding images on each glass shard.

The director wanted each glass shard exiting the screen to be accompanied by impactful and abstract sound art that choreographed with one of the victim's visual traumatic memories. Synchronising the sound design with the pathway of each glass shard and their discrete visual effects was complex. To streamline the process the sound designer was provided with an early outline of the glass breaking scene, minus the images of the victim's traumatic memories. Instead of containing the victim's memories, each shard was numbered so that its exiting pathway could be traced and sound could be synchronised as shown in Figure 1. This workflow helped to streamline, what had become an iterative post-production process and, more importantly it allowed for the three teams, editing, visual effects and sound design to work in parallel on the creation of this immersive multi-screen project.

The sonic palette for The Crossing was identified after considering a number of options that were trialled by the director and sound designer during the creative process. The sonic concept was agreed to revolve around an abstract approach that utilised diegetic sounds in a musical way, developing rhythm, volume dynamics and spectral features (i.e. bass, mid and high frequency components) that could be used as phrases and loops, whilst incorporating musical modulation effects such as reverb, delay, filtering, phasing and stereo panning.

The film uses two reoccurring sound beds throughout the feature; breathing and leaves rustling. The breathing provides a continuous rhythm component to the sound design and emphasizes both the human experience of the story and the journey of emotions as the narrative progresses. Starting as hopeful and relaxed, the breathing evolves to express fear and panic and, ultimately, relief at the point of the victim's rescue. The film completes with a huge exhale; a sigh of acceptance of a traumatised mind that is forced to live forevermore with memories of slavery and abuse. At both the start and end of the film, leaves rustle as diegetic sounds along with the rolling shot of leaves, and both times emphasizing the victim's relationship with nature and freedom, whilst also providing a random, yet sustained, high frequency sound that is intended to compliment the rhythmic nature and low frequency timbre of the breathing. 
A number of diegetic and Foley sounds are used in the film, which often evolve into hyperreal abstractions in order to expose the more sinister elements of the narrative. During the initial storytelling, sound design uses hopeful representations of travel to a new destination of opportunity, utilising sounds of the sea, birds and a boat engine, which becomes the train engine as the story's main character arrives in London. The train engine timbre is designed to evolve into the sound of an increasingly frantic heartbeat as the victim's scenario turns from hopeful to fearful, and the subsequent storyline leading up to her first experience of abuse at the hands of her traffickers. The sound design here takes a darker formant, utilising a synthesized low frequency helicopter sound, background city hum and distant police sirens of London night time and representations of the criminal underground. At this point the sound design synchronises with images projected on the victim's body; a stock market tickertape representing the black-market economy of human trafficking and the sound of a passport stamp representing ownership and control which the traffickers have over the victim. The sound used to represent the passport stamp is utilised from sound library audio of a punch bag hit, which ties sonically the abusive nature of the passport stamp with the physical abuse experienced.

The hyper-reality of diegetic sound takes a greater abstraction at the point of the victim's rescue, culminating visibly with the glass smash sequence and shards flying out towards the viewer. The sequence is displayed in slow motion and the initial glass break sound is taken from a sound library file of ice cracking, along with both high and low frequency transient impacts. The moving shards each represent a shifting memory of the victim and relate back to the hopeful and fearful emotions of the ordeal, whilst bringing an impactful surge to shock and disrupt the viewer. The sound of each shard purposefully evolves from a low-pass filtered version of the diegetic memory, sweeping sonically as the shard moves forwards towards the viewer. Each sound is modified dynamically with a resonant low pass frequency expanding higher to deliver a harsh, sharp sound, whilst also increasing in levels of volume, reverb and feedback delay. The resultant sound is impactful to the viewer as each shard approaches and exits the visual frame, whilst also leaving an abstract and overhanging decay profile that is soon overpowered by the proceeding shards. In particular, for this sequence, the sound design heavily utilised automated settings of Waves RVerb, Waves Supertap, Soundtoys FilterFreak, Soundtoys PhaseMistress and Soundtoys Crystalize music production plugins to achieve the desired hyper-real effect. 


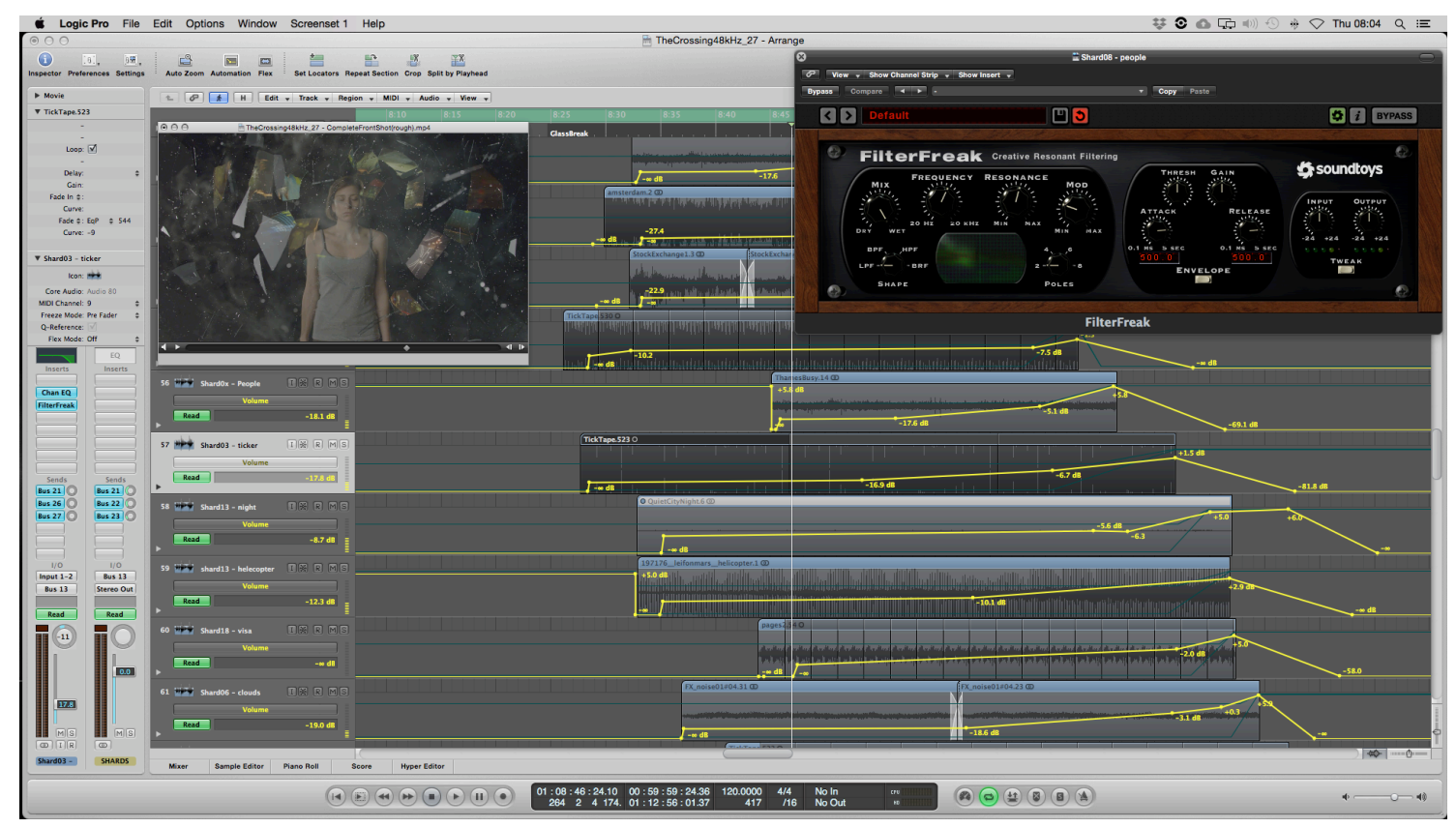

Figure 3. Logic Pro arrangement of the glass break sequence, with the Soundtoys FilterFreak processing tool highlighted.

A collaboration between the director, sound designer and voice actor, the spoken dialogue was recorded at a professional studio with particular attention given to recording clean (noise-free) and close, intimate dialogue. The voice actor was not given prior access to the script, in order to capture a first-read recording that maintained a sense of realism and an enforced slow pace of delivery. The second voiceover piece in The Crossing is the newsreel dialogue explaining statistics of human trafficking towards the end of the film. A number of voice actors were trailed for the newsreel dialogue, but were unable to deliver the speech in a manner representative of a trained newsreader. As a result, a local newsreader - Jeremy Sallis of BBC Cambridgeshire - was approached to provide the newsreel dialogue, which was recorded to script in the BBC Cambridgeshire news studio. To connect the film sonically with the criminal exploitation of humans in economically vulnerable communities, the newsreel dialogue is processed to be of perceivable low-quality, mimicking that of a cheap transistor radio, by processing the recorded dialogue with high- and low-pass filtering and subtle harmonic distortion. The newsreel dialogue is also designed to surround and encapsulate the listener, by sweeping the audio gently from left to right in the stereo field with use of the Waves MondoMod audio plugin. 
The intricate sound design was developed to provide an intimate and enclosed experience for the viewer, which was at odds with the objective to host the film in a multiscreen digital exhibition with freedom of movement for the audience. Loudspeaker playback experiments failed to deliver the desired sense of intimacy for the viewer, and as a result, Bluetooth headphones were chosen to deliver the audio, which also brings an advantage of portability in that the exhibition can be showcased in any multiscreen venue irrespective of the sound system installed. A number of digital Bluetooth transmitters and headsets were trailed, each with different performance levels; compromised quality of transmission and Bluetooth encoding was noticeable as noise during quiet or speech only passages of the film. A best suitable transmitter device was chosen and utilised for the showcase exhibition, however, it is anticipated that further advancement in Bluetooth audio transmission will offer future improvements to sound quality for multiscreen exhibitions such as The Crossing.

The use of Bluetooth headphones allowed the audience to have a consistent, personal and intimate experience, whilst being able to freely move around the exhibition space. Equally, the headphone setup ensured that participants did not interact with each other during the screening. Audience members were therefore enforced to internalise the film and the sound design experience, trapped in the film as the victim is trapped in their abuse. This solitary experience had impact, such that the viewer almost becomes the victim in the film, with the voiceover narrative potentially perceived as personal thoughts and heightening the emotive power of the rescue sequence in the film. These concepts are validated by audience feedback with respect to the sound design and headphone experience, as follows:

[the headphone experience] made the story feel extremely intimate and also minddisorientating later when the intense sound design kicked in.

I found the breathing distracting and upsetting ... like I want to do something to make this stop.

a synchronized experience, and brought me closer to the narrator, especially with the breathing at the end.

[I] couldn't escape.

The sound designer observed it was quite remarkable to watch people communally experiencing in pure silence 'some sort of deep reflective process of what they were watching and experiencing' (Toulson, 2017). 


\section{Conclusion}

The Crossing has been recognised by a number of awards both in industry and academia, including the Arts and Humanities Research Council, who described it as 'An ambitious and deftly executed film ...that pushes the boundaries of film and communication' (AHRC Research in Film Awards Panel, 2016). The audience testimonials provide personal accounts of the power of the immersive experience created by The Crossing and the complex and unconventional post-production workflow described how this sensitive subject matter was visually and aurally created for an immersive exhibition space. Through the construction of this project, the director investigated new approaches to immersive documentary filmmaking, the visual effects team explored technical approaches empowered by contemporary digital tools, and the sound designer experimented with a hybrid musical-diegetic approach that created an intimate story through sound. Overall the project allowed novel exploration of individual and collaborative craft skills to produce a powerful emotional response to an impactful film of real-world value.

\section{References}

Catmull E. (2014). Creativity, Inc. Great Britain: Transworld Publishers.

Dykhoff, K. (2016). Why Use Linear Workflows With Non-linear Tools? The New Soundtrack, 6(1), 51-61. Retrieved from

https://www.euppublishing.com/doi/full/10.3366/sound.2016.0082

Human Invent, (2017). The Evolution of Visual Effects in Films. Retrieved from: http://www.gizmodo.co.uk/2013/07/the-evolution-of-visual-effects-in-film/

International Labour Office (2014) Profits and Poverty: The economics of forced labour Retrieved from http://www.ilo.org/wcmsp5/groups/public/---ed norm/--declaration/documents/publication/wcms 243391.pdf

McQueen, S. (2009). Venice Biennale 2009: Interview with Steve McQueen Retrieved from https://www.youtube.com/watch?v=eJwbjG0HbnE 
Milisevic, M. (n.d.) Film Sound Beyond Reality: Subjective Sound in Narrative Cinema. Retrieved from http://filmsound.org/articles/beyond.htm\#sest6

Mayer, S. (2009). The Cinema of Sally Potter: a Politics of Love (Directors Cuts), New York, NY and London: Wallflower Press

Patel, S. (2017). The Crossing, Retrieved from https://vimeo.com/229111705

Patel, S. (2017). What happened when we showed a film about 'lover boy' sex trafficking to a group of teenagers Retrieved from https://theconversation.com/what-happened-when-we$\underline{\text { showed-a-film-about-lover-boy-sex-trafficking-to-a-group-of-teenagers-83478 }}$

Rose, J. (2009). Audio Post Production for Film and Video, 2nd Edition, Oxford: Focal Press.

Ross S., Esquire S. (n.d.) The State of the VFX Industry and where do we go from here. Retrieved from https://vimeo.com/66487005

United National Office on Drugs and Crime (2014) Global Report On Trafficking In Persons Profits and Poverty: The Economics of Forced Labour, International Labour Office, Geneva. Retrieved from https://www.unodc.org/res/cld/bibliography/global-report-on-trafficking-inpersons_html/GLOTIP_2014_full_report.pdf

Venkatasawmy R. (2012). The Evolution of VFX-Intensive Filmmaking in 20th Century Hollywood Cinema: An Historical Overview Retrieved from http://www.academia.edu/3361280/The Evolution of VFXIntensive_Filmmaking_in_20th_Century_Hollywood_Cinema_An_Historical_Overview

Wijaya, S T. (2017). Why filmmakers should focus on storytelling and not on special effects. Retrieved from http://www.thejakartapost.com/life/2017/01/17/why-filmmakers-shouldfocus-more-on-storytelling-not-special-effects.html

Yewdall, D. L. (2007). Practical Art of Motion Picture Sound, Elsevier, New York. 